\title{
ARTIFICIAL CARTILAGE BIO-MATRIX FORMED OF HYALURONIC ACID AND MG $^{2+}$-POLYPHOSPHATE
}

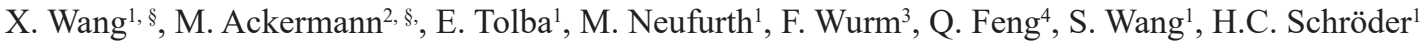 \\ and W.E.G. Müller ${ }^{1, *}$
}
${ }^{1}$ ERC Advanced Investigator Grant Research Group at the Institute for Physiological Chemistry, University Medical Centre of the Johannes Gutenberg University, Duesbergweg 6, D-55128 Mainz, Germany
${ }^{2}$ Institute of Functional and Clinical Anatomy, University Medical Centre of the Johannes Gutenberg University, Johann Joachim Becher Weg 13, D-55099 Mainz, Germany
${ }^{3}$ Department of Physical Chemistry of Polymers, Max Planck Institute for Polymer Research, Ackermannweg 10, D-55128 Mainz, Germany
${ }^{4}$ State Key Laboratory of New Ceramics and Fine Processing, School of Materials Science and Engineering, Tsinghua University, Beijing 100084, China

$\S$ These authors contributed equally

\begin{abstract}
Here we show that inorganic polyphosphate (polyP), a polyanionic metabolic regulator consisting of multiple phosphate residues linked by energy-rich phosphoanhydride bonds, is present in the synovial fluid. In a biomimetic approach, to enhance cartilage synthesis and regeneration, we prepared amorphous polyP microparticles with $\mathrm{Mg}^{2+}$ as counterions. The particles were characterised by $\mathrm{X}$-ray diffraction (XRD), energy-dispersive X-ray (EDX) and Fourier transformed infrared spectroscopic (FTIR) analyses. Similar particles were obtained after addition of $\mathrm{Mg}^{2+}$ ions to a solution containing hyaluronic acid, as a major component of the synovial fluid, and soluble NapolyP. The viscous paste-like material formed, composed of globular microparticles with diameter of $400 \mathrm{~nm}$, strongly promoted the adhesion of chondrocytes and caused a significant upregulation of the expression of the genes encoding collagen type 3A1, as a marker for chondrocyte differentiation, and $\mathrm{SOX} 9$, a transcription factor that regulates chondrocyte differentiation and proliferation. The expression level of the collagen type 3A1 gene was also enhanced by exposure of chondrocytes to synovial fluid that was found to contain polyP with a size of about 80 phosphate residues. This stimulatory effect was abolished after pre-incubation of the synovial fluid with the polyP degrading alkaline phosphatase. We propose a strategy for treatment of joint dysfunctions caused by osteoarthritis based on the application of amorphous $\mathrm{Mg}^{2+}$-polyP microparticles that prevent calcium crystal formation in the synovial fluid using scavenging $\mathrm{Ca}^{2+}$ ions $\left(\mathrm{Mg}^{2+} / \mathrm{Ca}^{2+}\right.$ exchange) and enhance chondrocyte function after binding of the $\mathrm{Ca}^{2+}$-polyP to hyaluronic acid at the cartilage surface.
\end{abstract}

Keywords: Cartilage, magnesium polyphosphate, hyaluronic acid, microparticles, synovial fluid, osteoarthritis, regenerative medicine, tissue engineering.

\footnotetext{
*Address for correspondence:

Prof Dr W.E.G. Müller

University Medical Centre of the Johannes Gutenberg University Mainz

D-55128 Mainz, Germany
}

Telephone number: +4961313925910

Fax number: +4961313925243

E-mail: wmueller@uni-mainz.de

\section{Introduction}

Osteoarthritis, the prevalent form of arthritis, is the most common form of joint disease and disability in older people (National collaborating centre for chronic conditions, 2008). It represents a complex musculoskeletal disorder that is associated with multiple genetic, constitutional and biomechanical risk factors (Murray and Lopez, 1997). It has been estimated that in the USA, in 2009, $\$ 185.5$ billion have been attributed to medical care for patients with osteoarthritis (Kotlarz et al., 2009). This disease, basically a broad clinical syndrome, is characterised by a progressive loss of articular cartilage and chondrocytes within the synovial joints that causes chronic joint pain and functional limitations (Sharma et al., 2013).

The existing data suggest that changes in cartilage and subchondral bone metabolism are not simply a passive process and a result of an increased vascularisation as well as microcrack formation in the joints, but an active dysregulation of the tuned communication and signalling pathways of the cartilage and the subchondral bone. In turn, it has been suggested that an elucidation of the functional behaviour of the chondrocytes and the osteoblasts in both physiological and pathophysiological conditions might be a rational and promising approach to develop effective strategies for a therapeutic intervention of osteoarthritis.

It is generally accepted that chondrocytes and osteoblasts are separate cell lineages that derive from common mesenchymal progenitor cells (reviewed in: Karsenty et al., 2009). However, evidence has been presented that terminally differentiated hypertrophic chondrocytes (Pacifici et al., 1990) can traverse to osteogenic cells both in foetal and postnatal endochondral bone (Yang et al., 2014). Osteoarthritis is characterised by a 20-fold increase in subchondral bone turnover and in an increased secretion of alkaline phosphatase (ALP) (Bailey et al., 2004), osteocalcin, osteopontin, IL-6 and IL-8 from subchondral bone explants in osteoarthritis patients (Mathy-Hartert et al., 2008). The enhanced bone anabolic 
activity of subchondral bone osteoblasts is not flanked by an equivalent mineralisation, resulting in the formation of osteoids (Day et al., 2001).

Ca-pyrophosphate and $\mathrm{Ca}$-phosphate crystals are frequently found in the synovial fluid and tissues of osteoarthritis patients (Gibilisco et al., 1984; Rosenthal, 2011). However, the role of those hydroxyapatite crystals as aetiological agents, during both initiation and progression of pathogenesis of osteoarthritis, remains controversial (McCarthy and Cheung, 2009; Pritzker, 2009). It has been observed that the expression of genes involved in mineralisation, e.g. human homologue of progressive ankylosis, plasma cell membrane glycoprotein 1 and tissue non-specific ALP, is upregulated in chondrocytes from osteoarthritis patients containing Ca-phosphate deposits in their cartilages. Based on those findings it is concluded that articular calcification, a well-known phenomenon occurring during late-stage osteoarthritis, is associated with those altered gene expressions (Nguyen et al., 2013).

The knee osteoarthritis is classified as either primary (idiopathic) or secondary. The hyaline joint cartilage, about 2 to $4 \mathrm{~mm}$ thick, is the main target where the disease starts. It is impressive that $95 \%$ of the hyaline cartilage consists of an extracellular matrix (Fox et al., 2009) which contains only sparsely distributed cells, the chondrocytes. This matrix is composed of water, aggrecan, collagen and proteoglycans; the latter component consists of decorin, biglycan and fibromodulin (Roughley and Lee, 1994). Aggrecan, the major proteoglycan in the articular cartilage, provides, together with the associated hyaluronic acid (HA, also termed hyaluronan), the cartilage with the proper hydrated gel structure and the required load-bearing properties (Kiani et al., 2002). HA is a potent hydrogel that allows the formation of a bulky network with water molecules. Different from most tissues, articular cartilage is not traversed by blood vessels, nerves or lymphatic vessels (reviewed in: Findlay, 2007). While the extracellular matrix has a low metabolism of collagen, the turnover rate of aggrecan is relatively high (Tchetina, 2011) with a calculated half-life of about 4 years (reviewed in: Sivan et al., 2014). It has been stressed by Ahlqvist et al. (1989) that cartilage requires a considerable amount of energy, which has been determined on the basis of oxygen consumption, with $0.01 \mu \mathrm{L} \mathrm{O}_{2} / \mathrm{h}$ per mg dry joint cartilage, a value which is in the range of the one measured for carotid body tissue (Starlinger and Lübbers, 1976). Glucose is considered as the major energy supply molecule for cartilage tissue (Mobasheri et al., 2002). This metabolite with its glucosederived sugars, e.g. glucosamine sulphate and vitamin $\mathrm{C}$, has been attributed as the key molecule controlling development, maintenance, repair and remodelling of cartilage. However, glucose has to enter the cells before it can provide energy in the form of ATP. Furthermore, it has been proposed that degeneration of cartilage might be caused by a glucose imbalance. However, still unclear is by which route glucose is transported within the cartilage. In turn, cartilage canals, existing in larger abundance in developing cartilage tissue, have been implicated in the supply of nutrients to the chondrocytes (Yamakura et al., 2001).
ATP receptors $\mathrm{P} 1$ (adenosine) and $\mathrm{P} 2$ (purine) (Koolpe et al., 1999) are integrated in the chondrocyte cell membrane and from here ATP can be released by chondrocytes in the chondrons (Elfervig et al., 2001). ATP has also been identified in the synovial fluid and it is considered to be a substrate for the production of inorganic pyrophosphate (Ryan et al., 1991). However, since pyrophosphate is a substrate for ALP (Moss et al., 1967; O'Neill, 2006) and ALP exists in the synovial fluid (Nanke et al., 2002), it is doubtful that ATP is present in larger amounts and in a soluble state separated from the cell surface. As such, the question still remains open as to from where the metabolic energy, different from ATP and required for the maintenance of the extracellular metabolically usable energy, the metabolic fuel, comes from. In addition, it has been proposed that mechanical energy (elastic energy) is stored in the collagen fibrils within the cartilage (Silver et al., 2002).

Recently, our group provided experimental evidence that polyphosphate (polyP), abundantly present both intracellularly and extracellularly as well as in blood platelets (Morrissey et al., 2012), could serve as an energy source for the generation of chemically utilisable Gibbs free energy after cleavage by ALP (reviewed in: Müller et al., 2015a; Wang et al., 2016). Blood platelets exist in large numbers in synovial fluids from patients with rheumatoid arthritis but are scarce in fluids from osteoarthritis patients, where the density varies between 0 and $10,000 / \mathrm{mm}^{3}$ (Farr et al., 1984). In turn, it can be predicted that the synovial fluid is rich in polyP. As a therapeutical consequence, platelet-rich plasma which has been injected into knees of osteoarthritis patients, was found to be superior compared to an application of HA (Raeissadat et al., 2015). Whereas HA, acting as a potential joint lubricant, has been proposed to ameliorate the pathophysiological symptoms of osteoarthritis by acting through CD44 receptors at the chondrocyte surface (Akmal et al., 2005).

In previous studies, it has been shown that polyP, prepared by gravity sintering at $950{ }^{\circ} \mathrm{C}$ and resulting in the formation of 75-150 $\mu \mathrm{m}$ large particles (Pilliar et al., 2001) causes a strengthening of the interfacial cartilage in vitro (St-Pierre et al., 2012). However, polyP is not present in the crystalline form in intact cells but as an amorphous polymer (Morrissey et al., 2012). In order to approach the physiological situation in a biomimetic way, we introduced a fabrication process that allows the preparation of amorphous microparticles of polyP (Müller et al., 2015b). Initially, those particles have been prepared with $\mathrm{Ca}^{2+}$ as the counterion to the phosphate groups within the polyP. $\mathrm{Ca}^{2+}$ was found also to self-organise and harden the gel-like polyP after bioprinting (Müller et al., 2015c). Since the aim of the present study is to outline a strategy for the injection of polyP-containing microparticles into the synovial fluid, amorphous polyP microparticles have been prepared with $\mathrm{Mg}^{2+}$ as counterions (Mg-polyP). With this approach, it is anticipated that the $\mathrm{Ca}^{2+}$ concentration in the fluid will decrease and prevent the propensity to form $\mathrm{Ca}^{2+}$ crystals; Mg-polyP will chelate out $\mathrm{Ca}^{2+}$ from the fluid to bind those to microparticles. Furthermore, $\mathrm{Mg}^{2+}$ has the potency to retard the nucleation and growth of Ca-phosphate crystals (Nabiyouni et al., 2015). 
$\mathrm{HA}$ is an anionic polymer that can bind $\mathrm{Ca}^{2+}$ even if incorporated into crystal particles (Lamontagne et al., 2011). In addition, HA is present in considerable amount (3-4 mg/mL) in the synovial fluid (Nitzan et al., 2001). Based on these findings, we developed here a strategy that uses $\mathrm{Mg}$-polyP microparticles as active components in a potential injection fluid that is able to bind $\mathrm{Ca}^{2+}$ (perhaps coming from the synovial fluid), which in turn forms a less soluble Ca-polyP (calcium-polyP) together with HA and could act as an artificial cartilage surface (Schmidt and Sah, 2007). The data obtained show that Mg-polyP microparticles, in the presence of HA, potentiate the gene expression of collagen type $3 \mathrm{~A} 1$ as well as the expression of the transcription factor SOX9, crucial proteins involved in the differentiation of chondrocytes during cartilage repair (Salminen et al., 2001). Based on the results elaborated here, we conclude that in the synovial fluid, which contains polyP, as well as HA (Decker et al., 1959) and $\mathrm{Ca}^{2+}$ (shown in the present study), the anionic, nonsulphated glycosaminoglycan interacts in the fluid with the anionic phosphate polymer using divalent cations, e.g. $\mathrm{Mg}^{2+}$ or $\mathrm{Ca}^{2+}$. This view adds for the first time a regulatory/ controlling system, existing in the synovial fluid, to our understanding of the anabolic pathway of the cartilage. Until now, only the omega- 3 fatty acids have been claimed to be stimulatory to anabolic processes of the cartilage metabolism (Jerosch, 2011). For the polyP paste formation, we used $\mathrm{Mg}^{2+}$ instead of $\mathrm{Ca}^{2+}$ in order to cause a less strong ionic bonding between the two polyanions HA and polyP. This approach also might allow the dissolution of the bone splinters that are found in the synovial fluid around damaged articular cartilage (Tew and Hackett 1981). As a consequence of the exchange of $\mathrm{Ca}^{2+}$ with $\mathrm{Mg}^{2+}$, a breakup of the hydroxyapatite crystals might be achievable.

\section{Materials and Methods}

\section{Materials}

Sodium polyphosphate (Na-polyP with an average chain of 40 phosphate units) was obtained from Chemische Fabrik Budenheim (Budenheim, Germany). Hyaluronic acid (HA, sodium salt from rooster comb, \#H5388) was obtained from Sigma-Aldrich (Taufkirchen, Germany).

\section{Preparation of polyP microparticles}

The fabrication of amorphous Ca-phosphate microparticles (aCa-polyP-MP) was performed as previously described (Müller et al., 2015b; Müller et al., 2015d). In short, $2.8 \mathrm{~g}$ of $\mathrm{CaCl}_{2} \cdot 2 \mathrm{H}_{2} \mathrm{O}$ (\#223506, Sigma-Aldrich, Taufkirchen, Germany) were dissolved in $25 \mathrm{~mL}$ of distilled water and added dropwise to $1 \mathrm{~g}$ of Na-polyP in $25 \mathrm{~mL}$ distilled water at room temperature. The suspension, kept at $\mathrm{pH} 10$, was stirred for $12 \mathrm{~h}$. The microparticles formed were collected by filtration, washed with ethanol and dried at $50{ }^{\circ} \mathrm{C}$.

The amorphous $\mathrm{Mg}$-phosphate microparticles (aMgpolyP-MP) were prepared similarly. To each $1 \mathrm{~g} \mathrm{Na}$ polyP, $3.86 \mathrm{~g}$ of $\mathrm{MgCl}_{2} \cdot 6 \mathrm{H}_{2} \mathrm{O}$ (\#A537.1, Roth, Karlsruhe, Germany) were added.

\section{Microstructure analyses}

$\mathrm{X}$-ray diffraction (XRD) experiments were performed as described previously (Raynaud et al., 2002). The patterns were registered on a Philips PW 1820 diffractometer (Philips, Eindhoven; the Netherlands) with $\mathrm{CuK} \alpha$ radiation $(\lambda=1.5418 \AA, 40 \mathrm{kV}, 30 \mathrm{~mA})$ in the range $2 \theta=5-65^{\circ}$ $(\Delta 2 \theta=0.02, \Delta \mathrm{t}=5 \mathrm{~s})$. Fourier transformed infrared spectroscopic (FTIR) analyses were performed with micromilled powder in an ATR (attenuated total reflectance)FTIR spectroscope/Varian 660-IR spectrometer (Agilent, Santa Clara, CA, USA), fitted with a Golden Gate ATR unit (Specac, Orpington, UK), as previously described (Müller et al., 2015b).

Scanning electron microscopic (SEM) imaging was performed using a Hitachi SU-8000 electron microscope (Hitachi High-Technologies Europe GmbH, Krefeld, Germany).

For energy-dispersive X-ray (EDX) spectroscopy, an EDAX Genesis EDX System attached to the scanning electron microscope (Nova 600 Nanolab, FEI, Eindhoven, The Netherlands) and operating at $10 \mathrm{kV}$ with a collection time of 30-45 s was used.

The inductively coupled plasma mass spectrometry analyses (ICP-MS) were performed with an Agilent 7500 Series ICP-MS quadrupole system (Agilent, Santa Clara, CA, USA).

\section{Coating of well plates with polyP-Mg ${ }^{2+}-\mathrm{HA}-\mathrm{Mg}^{2+}$}

Each well of 24-well plates (\#CLS3526, Sigma-Aldrich, Taufkirchen, Germany) was filled with $0.5 \mathrm{~mL}$ of saline supplemented with $10 \% \mathrm{HA}[\mathrm{w} / \mathrm{v}]$ and with $0.5 \mathrm{~mL}$ of saline containing $10 \% \mathrm{Na}$-polyP [w/v]. Subsequently, $1 \mathrm{~mL}$ of $\mathrm{MgCl}_{2} \cdot 6 \mathrm{H}_{2} \mathrm{O}(50 \mathrm{mg} / \mathrm{mL}$ saline $)$ was added, through which the gelation/ionic cross-linking reaction was initiated. The obtained HA-hydrogel, $\mathrm{Mg}^{2+}-\mathrm{Na}-$ polyP, was allowed to stand for $1 \mathrm{~h}$ to assure complete gelation (at room temperature). The fluid, released from the hydrogel, was removed carefully with a pipette. In the control, the wells were either supplemented with HA alone $(50 \mathrm{mg} / 0.5 \mathrm{~mL})$ or with Na-polyP $(50 \mathrm{mg} / 0.5 \mathrm{~mL})$. Most of the fluffs formed in the HA/Na-polyP assay attached to the bottom of the well plates. After standing at $37{ }^{\circ} \mathrm{C}$ for $4 \mathrm{~h}$, the fluid supernatant was aspirated and removed; then, $1.5 \mathrm{~mL}$ of medium (CGM, Chondrocyte Growth Medium, \#CC-3216; Lonza, Cologne, Germany)/ $10 \%$ foetal bovine serum (FBS) were added. Cells (10,000/well) were added and the cultures were inspected after $1 \mathrm{~h}$ or $3 \mathrm{~h}$ of incubation after staining with DAPI (4',6-diamidino-2phenylindole; Sigma-Aldrich, Taufkirchen, Germany). The slices were inspected with an Olympus AHBT3 microscope (Olympus, Hamburg, Germany).

\section{Binding studies of polyP to $\mathrm{HA}$}

In a final assay of $0.5 \mathrm{~mL}$ saline, $50 \mathrm{mg}$ of soluble polyP (added as Na-polyP) were added to $50 \mathrm{mg}$ of HA in a centrifugation tube. HA was spiked with $0.1 \mathrm{mCi}$ acetylated hyaluronic acid (acetyl- $\left.{ }^{3} \mathrm{H}\right)(250 \mathrm{mCi} / \mathrm{g}$; American Radiolabeled Chemicals, St. Louis, MO, USA). Where indicated, $100 \mu \mathrm{L}$ of diluted synovial fluid (1:100 dilution) were also added. Finally $100 \mu \mathrm{L}$ of $500 \mathrm{mM} \mathrm{MgCl}_{2}$ were 

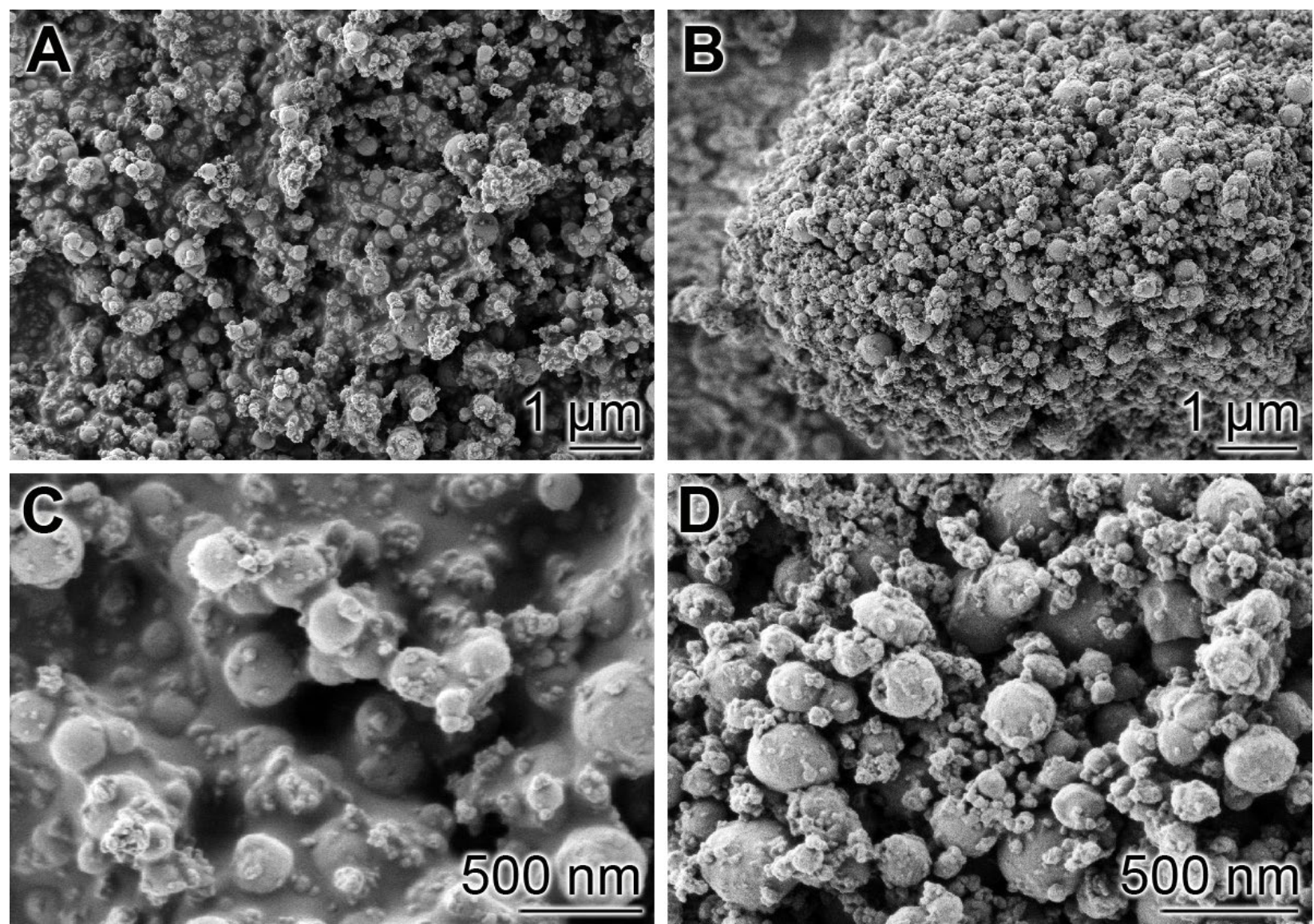

Fig. 1. Morphology of the amorphous (A, C) Ca-polyP microparticles (aCa-polyP-MP) and the (B, D) Mg-polyP particles (aMg-polyP-MP) observed with SEM.

supplemented to the reaction mixture and the incubation $\left(30^{\circ} \mathrm{C}\right.$ ) was performed for $15 \mathrm{~min}$ or $90 \mathrm{~min}$, as outlined in the results. Then the samples were centrifuged $(5 \mathrm{~min}$ at $5000 \times g$ ) and the respective sediments formed were transferred into $10 \mathrm{~mL}$ scintillation liquid (MP Biomedicals China, Shanghai 201201, China) and counted in a liquid scintillation spectrometer.

\section{Human chondrocyte}

Human chondrocytes, isolated from human knee, were purchased from Lonza ( NHAC-kn, \#CC-2550, Lonza, Cologne, Germany,). They were cultivated in CGM which contains growth factors and $5 \% \mathrm{FBS}$. The cells were subcultured when they reached $80 \%-90 \%$ confluency. They were seeded with a density of about 10,000 cells $/ \mathrm{cm}^{2}$ and cell number duplicated about every $60 \mathrm{~h}$.

\section{Identification of polyP in the synovial fluid}

For a qualitative analysis, $20 \mathrm{~mL}$ of freshly taken synovial fluid (approved by the ethical commission of the University Medical Centre, Mainz, Germany, 20160506) were used for the extraction of polyP, as previously described (Clark et al., 1986; Imsiecke et al., 1996). The polyP fraction obtained was applied onto a $7 \mathrm{M}$ urea/16.5\% polyacrylamide gel and stained with $o$-toluidine blue. PolyP standards of defined chain lengths were run in parallel (Lorenz and Schröder, 2001).

Where indicated, the synovial fluid was pre-incubated with 20 units of ALP/mL synovial fluid. The recombinant bovine ALP, expressed in Pichia pastoris (\#P8361; Sigma-
Aldrich, Taufkirchen, Germany) was used for this study; incubation was performed for $6 \mathrm{~h}$ at room temperature prior to addition of the synovial fluid to the chondrocytes.

\section{Gene expression studies}

The technique of quantitative real-time reverse transcription polymerase chain reaction (qRT-PCR) was applied to determine semi-quantitatively the effect of the polyP samples on chondrocytes. The cells were incubated for $0 \mathrm{~d}$ or $21 \mathrm{~d}$ in the absence of polyP or in the presence of $50 \mu \mathrm{g} / \mathrm{mL}$ of Na-polyP or onto slides, that had been coated either with $300 \mu \mathrm{L}$ of $\mathrm{HA}(10 \mathrm{mg} / \mathrm{mL}$ saline supplemented with $5 \mathrm{mM} \mathrm{MgCl}$ ) or $300 \mu \mathrm{L}$ of HA/Na-polyP (10 mg of $\mathrm{HA} / 10 \mathrm{mg}$ of Na-polyP in $5 \mathrm{mM} \mathrm{MgCl}_{2}$ ).

In one series of experiments, chondrocytes were incubated with synovial fluid (1:100 dilution) for $21 \mathrm{~d}$. In order to remove polyP, present in the synovial fluid, the samples were pre-incubated with ALP, as described above.

The technical details for the qRT-PCR have been given earlier (Wiens et al., 2010). The following two genes were selected to determine the activation state of the human chondrocytes; SOX9 SRYbox 9 (NM_000346) with the primer pair Fwd: 5'-TGCTGCTGGGAAACATTTGCAC-3' $\left(\mathrm{nt}_{2762}\right.$ to nt $_{2783}$ ) and Rev: 5'-GGGCACTTATTGGCTGCTGAAAC-3' $\left(\mathrm{nt}_{2901}\right.$ to $\mathrm{nt}_{2879} ; 140 \mathrm{bp}$ ) and second COL3A1 (collagen type III alpha 1; NM_000090) with the primer pair Fwd: 5'-ATTCCTTCGAC TTCTCTCCAGCC-3' (nt $_{4182}$ to $\mathrm{nt}_{4204}$ ) and Rev: 5'-GTGTTTCGTGCAACCATCCTCC-3' $\left(\mathrm{nt}_{4377}\right.$ to $\left.\mathrm{nt}_{4356} ; 196 \mathrm{bp}\right)$. The expression levels of 
these transcripts were correlated to the reference housekeeping gene GAPDH (glyceraldehyde 3-phosphate dehydrogenase; NM_002046.3) with the primer pair Fwd: 5'-ACTTTGTGAAGCTCATTTCCTGGTA-3' ( nt $_{1019}$ to $\mathrm{nt}_{1043}$ ) and Rev: 5'-TTGCTGGGGCTGGTGGTCCA-3' $\left(\mathrm{nt}_{1136}\right.$ to $\mathrm{nt}_{1117} ; 118 \mathrm{bp}$ ). The qRT-PCR experiments were performed in an iCycler (Bio-Rad, Hercules, CA, USA); the mean $\mathrm{Ct}$ values and efficiencies were calculated with the iCycler software (Bio-Rad, Hercules, CA, USA); the estimated PCR efficiencies range between $93 \%$ and $103 \%$ (Pfaffl, 2001).

\section{Statistical analysis}

After finding that the respective values followed a standard normal Gaussian distribution and that the variances of the respective groups were equal, the results were statistically evaluated using the independent two-sample Student's $t$ test (Petrie and Watson, 2013).

\section{Results}

\section{Fabrication of polyP microparticles and their characterisation}

As described in Materials and Methods, microparticles were prepared from Ca-polyP as well as from $\mathrm{Mg}$-polyP. The size range of the aCa-polyP-MP varied between 220 and $535 \mathrm{~nm}$ (average $352 \pm 122 \mathrm{~nm}$ ) (Fig. 1A, C), while the dimensions of the aMg-polyP-MP were slightly smaller, between 130 and $317 \mathrm{~nm}$ (average $245 \pm 138 \mathrm{~nm}$ ) (Fig. 1B, D).

Element analysis of the polyP microparticles was performed by EDX. The spectra showed for the aCapolyP-MP pronounced peaks for $\mathrm{Ca}, \mathrm{P}$ and $\mathrm{O}$, while only minor signals appeared for $\mathrm{C}$ and $\mathrm{Na}$ (Fig. 2A). The pattern for aMg-polyP-MP showed distinct peaks for $\mathrm{Mg}, \mathrm{P}$ and $\mathrm{O}$ and again only small ones for $\mathrm{C}$ and $\mathrm{Na}$ (Fig. 2B). A quantitative analysis of the particles was performed by ICP-MS. The final divalent cation/P atomic ratio for the obtained aCa-polyP-MP was $0.93 \pm 0.12$ and for aMgpolyP-MP $0.81 \pm 0.09$ (data not shown).

The FTIR spectra of the microparticles, aCa-polyP-MP and aMg-polyP-MP, showed strong absorption bands in the

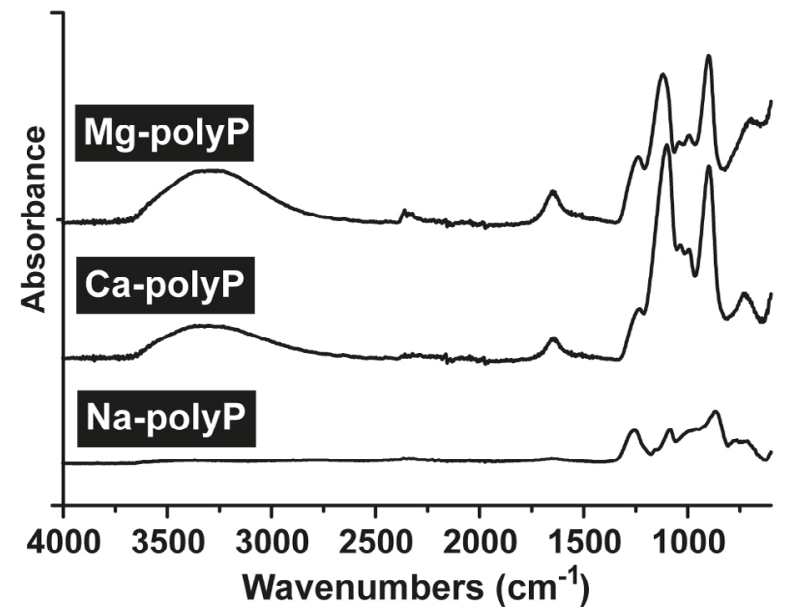

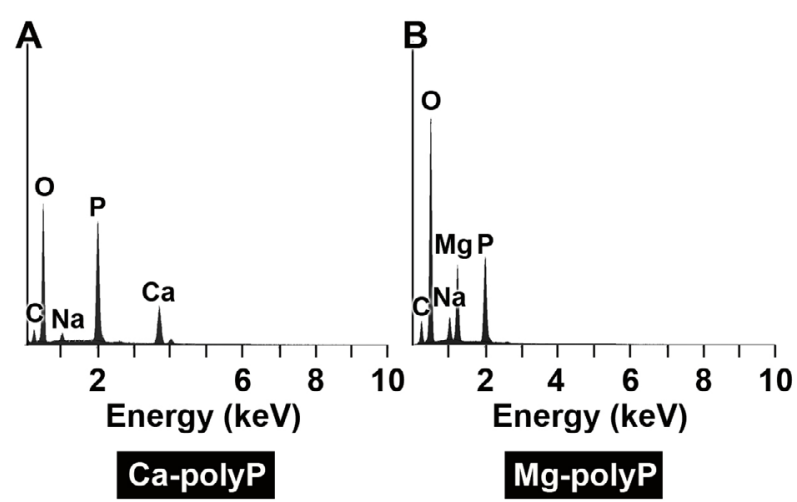

Fig. 2. EDX spectra of (A) aCa-polyP-MP and (B) aMgpolyP-MP. The signals for the elements $\mathrm{C}, \mathrm{O}, \mathrm{Na}, \mathrm{Mg}, \mathrm{P}$ and $\mathrm{Ca}$ are marked.

low and high frequency regions, due to phosphate moieties and the $\mathrm{OH}$ groups (Fig. 3). On the basis of the literature data (Szumera, 2014; Crobu et al., 2012; Yifen et al., 1986), the bands recorded could be attributed to the vibrations of the following structural units: the peaks at $\sim 3400 \mathrm{~cm}^{-1}$ and $1627 \mathrm{~cm}^{-1}$ were mainly assigned to the $\mathrm{OH}$ stretching and bending vibrations of adsorbed water; the band near $1261 \mathrm{~cm}^{-1}$ was designated to the asymmetric stretching of the $\mathrm{P}=\mathrm{O}$, i.e. $v_{\text {as }}\left(\mathrm{PO}_{2}\right)^{-}$. The weaker band at $1196 \mathrm{~cm}^{-1}$ (not marked in Fig. 3) reflected the $\mathrm{PO}_{2}$ symmetric stretching mode $v_{\mathrm{s}}\left(\mathrm{PO}_{2}\right)^{2}$; the absorption bands close to $1083 \mathrm{~cm}^{-1}$ and $999 \mathrm{~cm}^{-1}$ were assigned to the asymmetric and symmetric stretching modes of chain-terminating $\mathrm{PO}_{3}$ groups $\left[v_{\text {as }}\left(\mathrm{PO}_{3}\right)^{2-}\right.$ and $\left.v_{\mathrm{s}}\left(\mathrm{PO}_{3}\right)^{2-}\right]$; the absorption band near $864 \mathrm{~cm}^{-1}$ was assigned to the asymmetric stretching modes of the P-O-P linkages, $v_{\text {as }}(\mathrm{P}-\mathrm{O}-\mathrm{P})$ and the partially split band was centred around $763 \mathrm{~cm}^{-1}$ and was assigned to the symmetric stretching modes of the $v_{\mathrm{s}}(\mathrm{P}-\mathrm{O}-\mathrm{P})$. A comparison between the spectra of Na-polyP, Ca-polyP and Mg-polyP showed the common feature for polyP in the $1300-600 \mathrm{~cm}^{-1}$ region. Those signals reflected the polyP backbones and were not broken down during the reaction with the $\mathrm{Ca}^{2+}$ or $\mathrm{Mg}^{2+}$. However, the peaks shifted in the Ca-polyP and $\mathrm{Mg}$ polyP samples, if compared to those in Na-polyP. These changes in the phosphate structures were attributed to the $\mathrm{Ca}^{2+}$ or $\mathrm{Mg}^{2+}$ ions, which generally provide ionic cross-

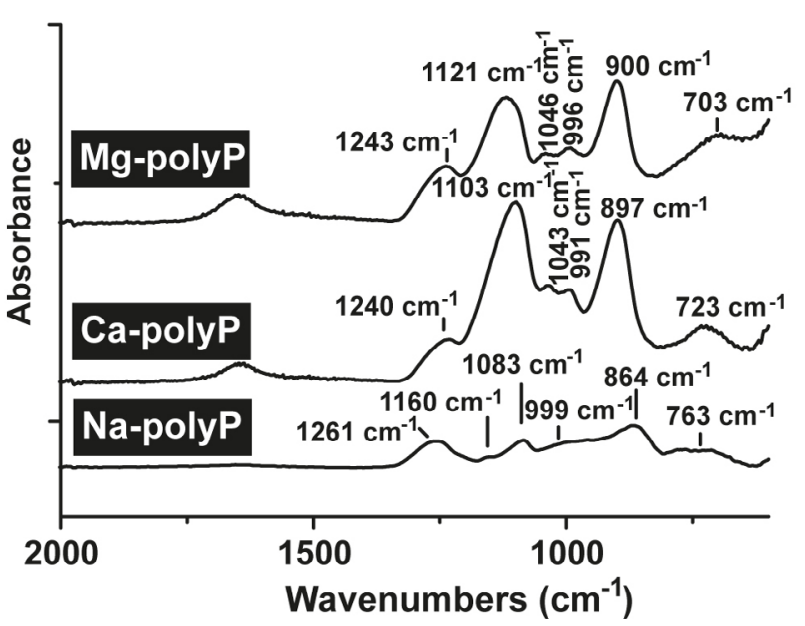

Fig. 3. FTIR spectra of Na-polyP, Ca-polyP and Mg-polyP as recorded between the wavenumbers $4000 \mathrm{~cm}^{-1} \mathrm{and}^{-1}$ $700 \mathrm{~cm}^{-1}$; on the right is shown an enlargement of the range between $2000 \mathrm{~cm}^{-1}$ and $700 \mathrm{~cm}^{-1}$. 
linking between non-bridging oxygen of the phosphates groups. Those $\mathrm{Ca}^{2+}$ and $\mathrm{Mg}^{2+}$ caused cross-links further increased the interacting bond strength between adjacent polyP chains. Additionally, the modification in the polyP structures could be understood further on the basis of the changes in the respective terminal charge densities at an anionic site, i.e. at the sites of formation of $\mathrm{P}-\mathrm{O}-\mathrm{M}$ (where $\mathrm{M}$ is $\mathrm{Ca}^{2+}$ or $\mathrm{Mg}^{2+}$; in Na-polyP at $1261 \mathrm{~cm}^{-1}$, in Ca-polyP at $1240 \mathrm{~cm}^{-1}$ and in Mg-polyP at $1243 \mathrm{~cm}^{-1}$ ). Thus, IR spectra confirmed the ionic interactions between the two divalent cations and the respective polyP chains formed within Ca-polyP and Mg-polyP.

Fig. 4 shows the XRD patterns of Na-polyP, Ca-polyP and Mg-polyP powder samples. While Na-polyP was used as an unchanged salt sample, microparticles were prepared from Ca-polyP and Mg-polyP. All these samples were obtained after drying at $60^{\circ} \mathrm{C}$ for $24 \mathrm{~h}$. The absence of any sharp peak confirmed the absence of any crystalline phase, proving the amorphous structure of the microparticles (aCa-polyP-MP and aMg-polyP-MP, respectively). The amorphous phase is shown within the broad peak from $20^{\circ}$ to $40^{\circ}$ (theta) degrees for Na-polyP and for Ca-polyP and $\mathrm{Mg}$-polyP around $30^{\circ}$ (theta) degrees.

\section{In situ formation of Mg-polyP microparticles and their interaction with $\mathrm{HA}$}

The formation of Mg-polyP microparticles from Na-polyP and HA was processed in 24-well plates, starting from $50 \mathrm{mg} / 0.5 \mathrm{~mL}$ of Na-polyP and $50 \mathrm{mg} / 0.5 \mathrm{~mL}$ of $\mathrm{HA}$ in saline. This sample appeared as a perfect solution (Fig. 5A). If $\mathrm{MgCl}_{2} \cdot 6 \mathrm{H}_{2} \mathrm{O}$ was added, an almost immediate gelation process started that was visualised by an intense schlieren formation (Fig. 5B). It is suggested that those fibrillar/globular striae reflect the association between HA and polyP through $\mathrm{Mg}^{2+}$ ionic bonds.

The formed gel flakes attached to the glass slides and allowed an inspection by SEM (Fig. 6). Those aspects revealed that the microparticles formed from Na-polyP and $\mathrm{HA}$ and after addition of $\mathrm{Mg}^{2+}$ appeared as almost perfect spherical microparticles with an average size of $389 \pm 143$ nm (Fig. 6C, D). In contrast, HA flakes that attached onto the slides and produced from a solution of $\mathrm{HA}$ in saline without $\mathrm{Mg}^{2+}$ revealed a quite smooth coat (Fig. 6A, B). In assays with Na-polyP no flakes could be visualised after addition of $\mathrm{Mg}^{2+}$ (data not shown).

The binding affinity of HA to soluble polyP (as NapolyP) was measured with radioactively labelled $\left[{ }^{3} \mathrm{H}\right]$ HA as tracer as described in Materials and Methods. The schlieren formation was initiated with $\mathrm{MgCl}_{2}$ and the assay was performed for 15 and 90 min, respectively. Then the components were centrifuged and the radioactivity, present in the sediments, was determined. The data revealed that in the absence of polyP only very little radioactivity could be detected on the bottom of the tube ( $\approx 200 \mathrm{dpm})$. However, after a 15 min incubation period together with polyP an over 10-fold higher amount of radioactivity could be found on the bottom of the tube. This value did not change significantly after the longer $(90 \mathrm{~min})$ incubation period. If the synovial fluid was added to the reaction mixture $\left(\left[{ }^{3} \mathrm{H}\right]\right.$ HA and polyP) already a significant $(p<0.05)$ reduction to $3172 \pm 258 \mathrm{dpm}$ was measured in the sediment after

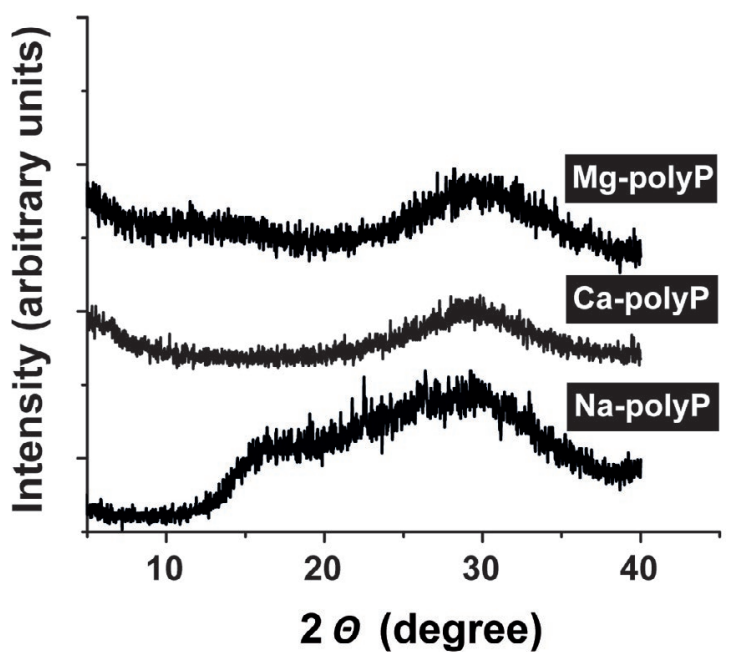

Fig. 4. XRD pattern obtained for both the unchanged Na-polyP as well as the microparticles prepared from $\mathrm{Ca}$-polyP and from $\mathrm{Mg}$-polyP. No characteristic signals are detected that would indicate some form of crystalline polyP material.

a 15 min incubation period; the decrease even became more pronounced if the reaction was extended to $90 \mathrm{~min}$ (1281 $\pm 295 \mathrm{dpm})$ (Table 1).

\section{Attachment of human chondrocytes onto $\mathrm{HA}-\mathrm{Mg}^{2+}-$ polyP-covered slides}

The propensity of chondrocytes to attach to differentially covered glass slides has been inspected $3 \mathrm{~h}$ after transfer of the cells onto the slides. The cells were visualised by staining with DAPI. After irradiation with fluorescent light it became evident that only a few cells attached to untreated glass surfaces after $3 \mathrm{~h}$ (Fig. 7A), while significantly more cells were visualised after $3 \mathrm{~h}$ on surfaces coated with HA (Fig. 7B). Comparably intense was the attachment of chondrocytes to glass slides that had been coated with HA-Mg ${ }^{2+}$-Na-polyP (Fig. 7C, D). Even after a short $1 \mathrm{~h}$ incubation period the cells abundantly attached to HA$\mathrm{Mg}^{2+}$-Na-polyP-coated slides (Fig. 7C), and even more cells were detected after $3 \mathrm{~h}$ incubation (Fig. 7D). While the morphology of the cells, growing onto untreated or onto HA-coated glass slides, showed a round and very rarely a polygonal shape, most of the cells that had been cultured onto HA-Mg ${ }^{2+}$-Na-polyP-coated slides had been polygonal.

\section{Expression of SOX9 and COL3A1 in response to polyP exposure}

Following the study published by Girotto et al. (2003), we selected the genes of the transcription factor SOX9 and of the collagen gene COL $3 \mathrm{~A} 1$ as reliable markers for in vitro studies of chondrocytes with respect to cartilage differentiation. We found that the transcript level of SOX9 changed during the $21 \mathrm{~d}$ incubation only if the cells were incubated onto the HA- $\mathrm{Mg}^{2+}$-Na-polyP matrix (Fig. 8A). While the expression of this gene only varied slightly if the cells were cultured in the absence of any additional component or only moderately with the two starting substrates, used for the formation of $\mathrm{HA}-\mathrm{Mg}^{2+}-\mathrm{Na}$-polyP [polyP (administered as Na-polyP) and HA], an almost 

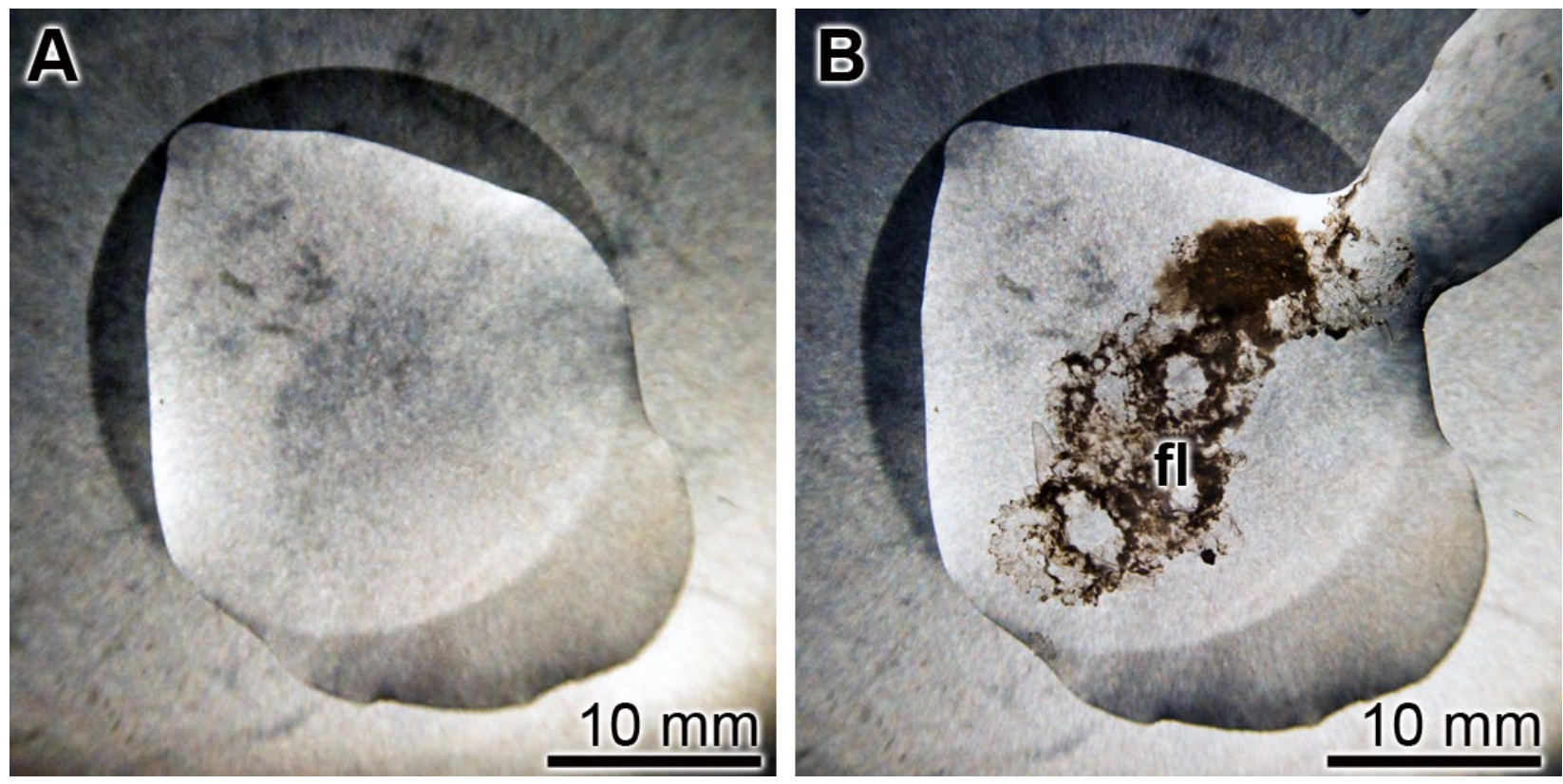

Fig. 5. Gel-formation of polyP with $\mathrm{HA}$ in the presence of $\mathrm{Mg}^{2+}$. (A) Mixing of $50 \mathrm{mg} / 0.5 \mathrm{~mL}$ of Na-polyP with $50 \mathrm{mg} / 0.5 \mathrm{~mL}$ of HA resulted in a clear solution. (B) If $\mathrm{Mg}^{2+}$ ions $\left(1 \mathrm{~mL}\right.$ of $\left.50 \mathrm{mg} \mathrm{MgCl} \cdot 6 \mathrm{H}_{2} \mathrm{O} / \mathrm{mL}\right)$ are added extensive flakes (fl) are formed. Those fibrillar/globular schlieren structures most likely reflect the association between $\mathrm{HA}$ and polyP through $\mathrm{Mg}^{2+}$ ionic bonds.

Table 1. $50 \mathrm{mg}$ of HA (spiked with radioactively labelled [acetyl $\left.-{ }^{3} \mathrm{H}\right] \mathrm{HA}$ ) were dissolved in saline and, where indicated, added to polyP (50 mg; added as soluble $\mathrm{Na}-$ polyP $)$ in a reaction tube; the final assay volume was $0.5 \mathrm{~mL}$. Then the incubation was performed in the absence or presence of $100 \mu \mathrm{L}$ of diluted synovial fluid, as outlined in Materials and Methods. Finally, $100 \mu \mathrm{L} 500 \mathrm{mM} \mathrm{MgCl} \cdot 6 \mathrm{H}_{2} \mathrm{O}$ were added and the incubation was run for $15 \mathrm{~min}$ or $90 \mathrm{~min}$, as indicated. The different components were added to $(+)$ or omitted from (-) the reaction mixture. At the end of the incubation period the material was centrifuged and the sediment was counted in a liquid scintillation spectrometer. The radioactivity in the sediment was determined ( $n=10$ separate experiments).

\begin{tabular}{|c|c|c|c|c|c|}
\hline $\begin{array}{c}\text { Assay } \\
\text { number }\end{array}$ & {$\left[{ }^{3} \mathbf{H}\right] \mathbf{H A}$} & polyP & $\begin{array}{c}\text { Synovial } \\
\text { fluid }\end{array}$ & $\begin{array}{c}\text { Incubation period (min) after addition of } \\
\mathbf{1 0 0} \boldsymbol{\mu L ~ o f ~ 5 0 0 ~} \mathbf{~ M ~ M g C l 2}\end{array}$ & $\begin{array}{c}\text { Radioactivity in } \\
\text { sediment dpm/assay }\end{array}$ \\
\hline 1 & + & - & - & 15 & $174 \pm 29$ \\
\hline 2 & + & - & - & 90 & $210 \pm 32$ \\
\hline 3 & + & + & - & 15 & $3792 \pm 248$ \\
\hline 4 & + & + & - & 90 & $3916 \pm 295$ \\
\hline 5 & + & + & + & 15 & $3172 \pm 258$ \\
\hline 6 & + & + & + & 90 & $1281 \pm 295$ \\
\hline
\end{tabular}

3-fold increase of the expression level was observed if the cells grew onto the HA- $\mathrm{Mg}^{2+}$-Na-polyP surface (Fig. 8A).

In contrast, the expression level of COL $3 \mathrm{~A} 1$ increased significantly during the $21 \mathrm{~d}$ incubation period by 2 -fold (with respect to day 0 ) or 1.7 -fold (with respect to control) if the chondrocytes were exposed to Na-polyP and even 5-fold (with respect to day 0) or 3.1-fold (with respect to controls) if the cells were cultured onto HA- $\mathrm{Mg}^{2+}-\mathrm{Na}-$ polyP, while only a slight increase was seen in the assay with HA (Fig. 8B).

\section{Tracing polyP in synovial fluid}

Since a direct quantification of polyP in synovial fluid, using the $o$-toluidine blue colour procedure (Clark et al., 1986), revealed only ambiguous results we investigated the existence of the polymer qualitatively using urea/ polyacrylamide gel electrophoresis instead. Applying this technique, polyP could be identified in the gel as a distinct band around the polyP marker size range of poly $\mathrm{P}_{80}$ (Fig.
9; lanes a-d); in this region no toluidine staining could be seen in the parallel lane (lane e), which did not contain any polyP. The intensity of Na-polyP $(20 \mu \mathrm{g} / \mathrm{slot})$ used for the preparation of the microparticles is seen in lane $\mathrm{f}$ (Fig. 9).

\section{Effect of synovial fluid on the collagen gene (COL3A1) expression}

To test the effect of human synovial fluid on the expression of collagen COL $3 \mathrm{~A} 1$ gene, the chondrocytes were incubated for $21 \mathrm{~d}$ in the standard assay. A 1:100 dilution of the fluid was applied and added at a concentration of $10 \mu \mathrm{L} /$ well or $30 \mu \mathrm{L} /$ well (Fig. 10). Using these conditions the expression of the gene strongly increased from the base level of 0.4 units with respect to the steady-state expression of the reference gene GAPDH to 3.82 units at $10 \mu \mathrm{g} /$ well or to 2.77 units at $30 \mu \mathrm{L} /$ well. However, this strong stimulatory activity was completely abolished if the synovial fluid was pre-incubated with ALP as described in Materials and Methods. 

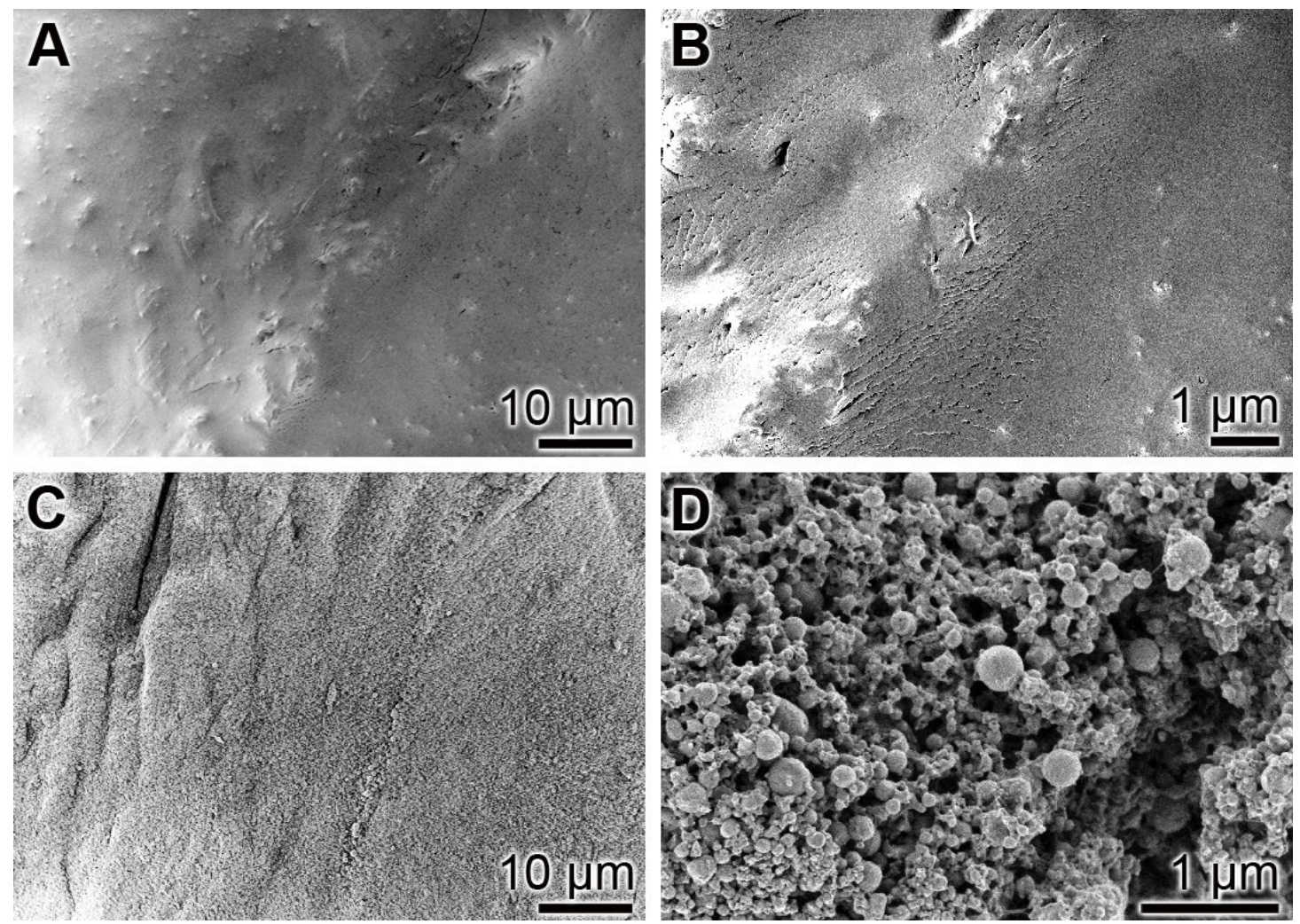

Fig. 6. SEM analysis of HA-polyP. (A, B) Analysis of a HA-polyP layer without addition of $\mathrm{MgCl}_{2}$. (C, D) Visualisation of the microparticles present in the flakes, formed from $\mathrm{HA}$ and $\mathrm{Na}$-polyP after addition of $\mathrm{MgCl}_{2}$.
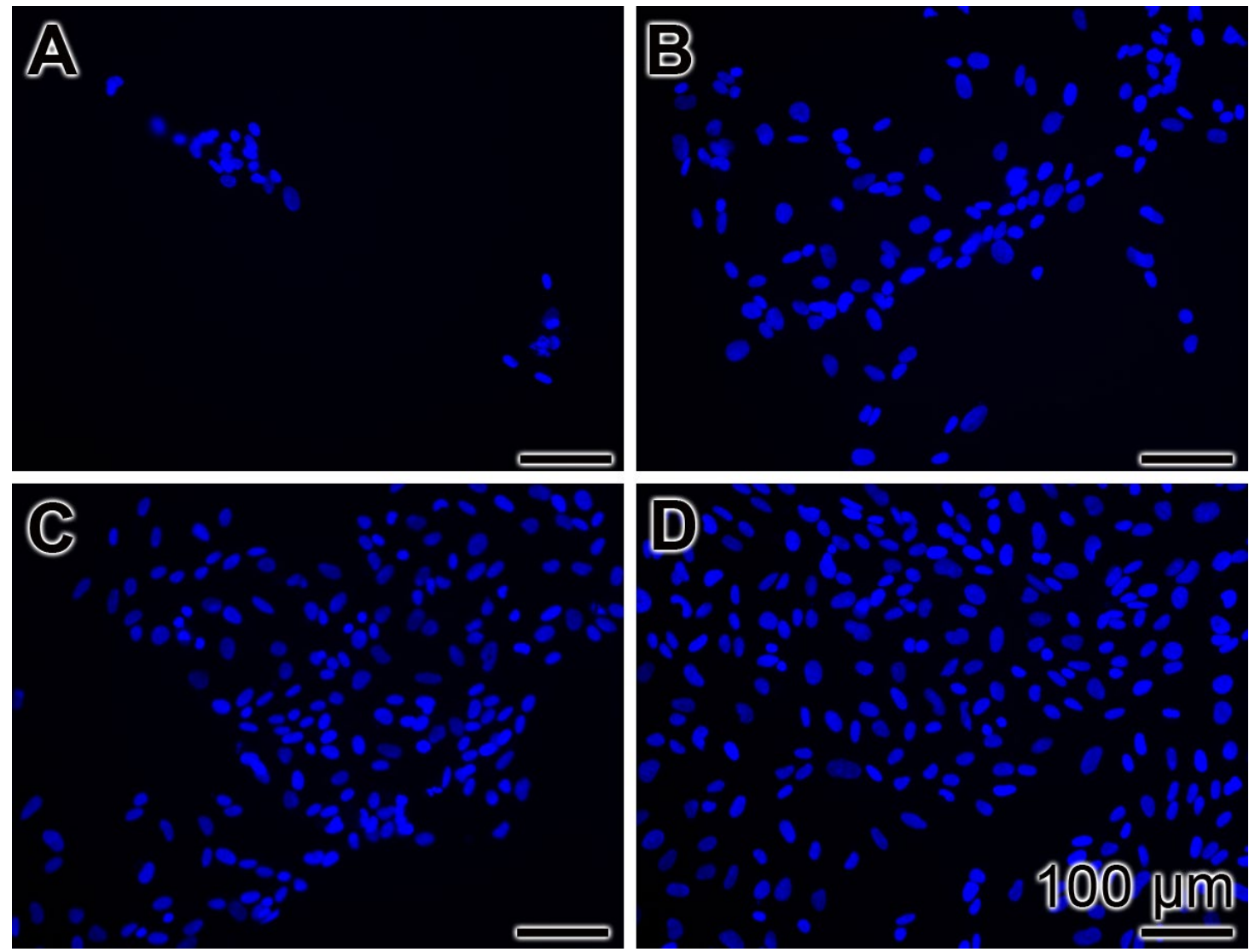

Fig. 7. Attachment of chondrocytes to (A) an untreated glass slide, (B) a HA-treated slide and (C, D) a HA-Mg ${ }^{2+}-$ Na-polyP-coated slide. The cells were cultivated onto the slides for $1 \mathrm{~h}(\mathbf{C})$ or $3 \mathrm{~h}(\mathbf{A}, \mathbf{B}, \mathbf{D})$. The nuclei of the cells were stained with DAPI. 

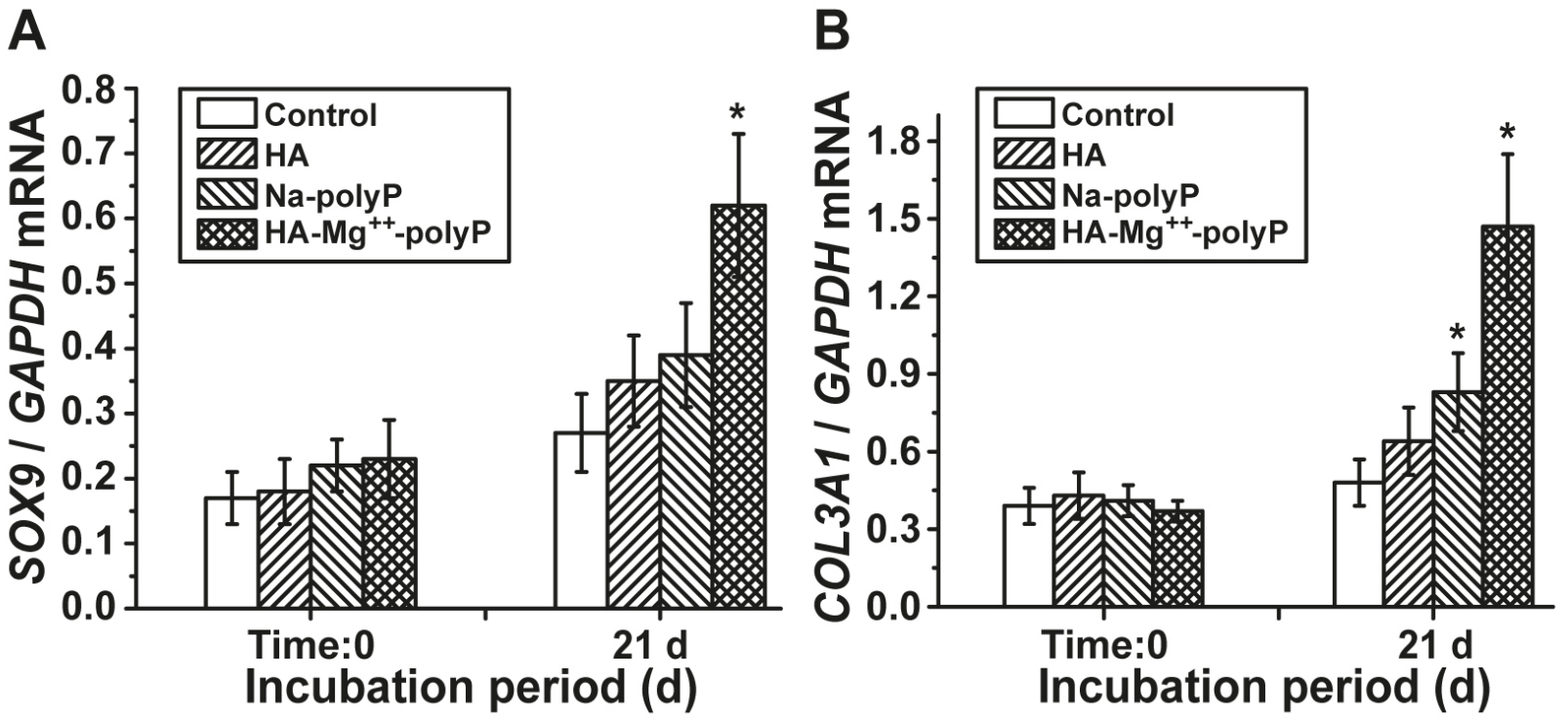

Fig. 8. Changes of transcript levels of SOX 9 and COL3A1 in chondrocytes during a $21 \mathrm{~d}$ incubation period. The cells were cultivated either in the absence of additional components (open bars), in the presence of soluble polyP,

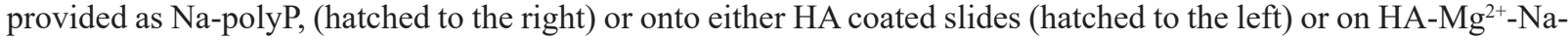
polyP matrices (filled bars). After incubation the RNA was extracted from the cells and then subjected to qRT-PCR. GAPDH expression level was chosen to normalise the transcript levels for SOX9 and COL3A1. Standard errors of the means (SEM) are indicated $\left(n=5\right.$ experiments per time point); ${ }^{*} p<0.05$.

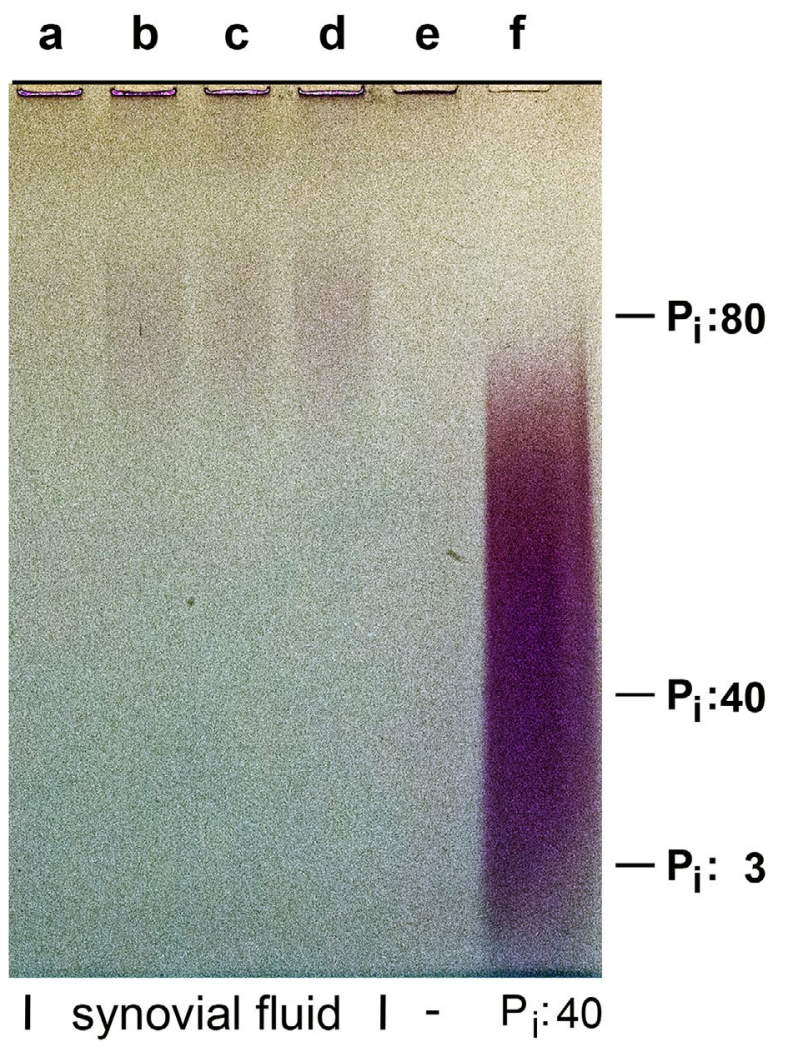

Fig. 9. Abundance and size of polyP, isolated from synovial fluid. Different concentrations of extracts from the synovial fluid were applied per lane; extracts from $10 \mathrm{~mL}$ of fluid (lane a), from $15 \mathrm{~mL}$ (lanes b, c) and $20 \mathrm{~mL}$ (lane d). Lane e remained empty (-) and f was loaded with $20 \mu \mathrm{g}$ of polyP $\mathrm{P}_{40}\left(\mathrm{P}_{i}: 40\right)$. Size markers of poly $\mathrm{P}_{80}$, poly $_{40}$ and poly $\mathrm{P}_{3}$ were run in parallel.

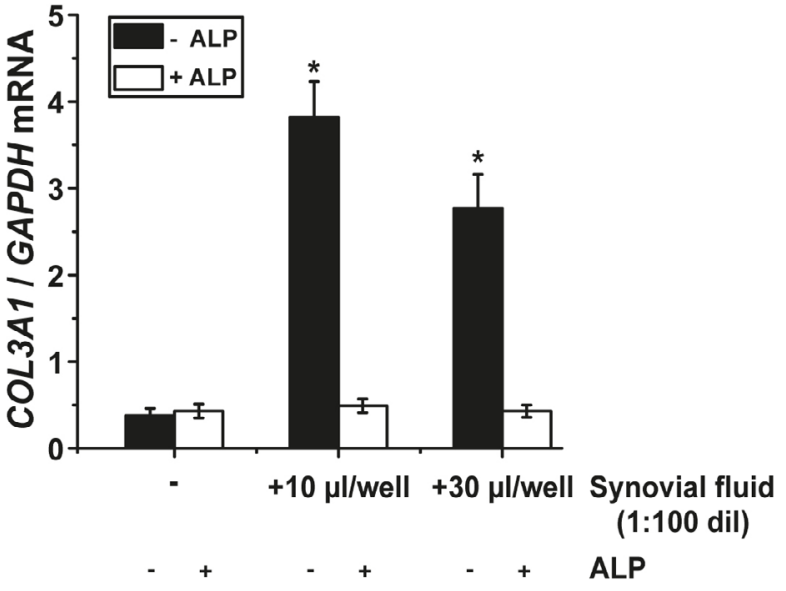

Fig. 10. Upregulation of COL $3 \mathrm{~A} 1$ gene expression by synovial fluid. The chondrocytes remained either unexposed to the synovial fluid (-) or were incubated with two different concentrations of the fluid (at a dilution of 1:100), with $10 \mu \mathrm{L} /$ well or $30 \mu \mathrm{L} /$ well. The synovial fluid (or saline in controls) remained either untreated with ALP (-) or was pre-incubated with the enzyme $(+)$ as described in Materials and Methods. The means \pm standard errors from five experiments per time point are shown; $* p<0.05$. 


\section{Discussion}

It is a fact that the cartilage bordering the synovial fluid has a low metabolism, both with respect to the turnover of collagen, aggrecan/proteoglycan and HA (see Introduction). However, as outlined above, deprivation of glucose in the synovial fluid, as a metabolic fuel for the chondrocytes, results in a slow-down of the metabolic rate in these cartilage-forming cells.

With the discovery, in the present study, that polyP is present in the synovial fluid and is most likely involved in the stimulation of collagen 3 (COL3A1), we provide strong experimental indications that polyP is one key regulator of the metabolic activity of chondrocytes and in turn of the extracellular matrix, consisting of ground substances (hyaluronan, chondroitin sulphates and keratan sulphate) and also tropocollagen which subsequently polymerises extracellularly into the collagen fibres (Fig. 8). In order to approach this potentially new pathway, which might trigger the chondrocytes to a higher rate of synthesis of those extracellular structural and functional polymers, experimentally, we prepared particles from $\mathrm{Mg}^{2+}$ and polyP, aMg-polyP-MP and proved that they were amorphous [by XRD (Fig. 4)] and comprised the expected chemical composition [by EDX (Fig. 2) and FTIR (Fig. 3)]. The sizes of those particles, prepared as a powder varied around $250 \mathrm{~nm}$ and by that they were slightly smaller than the amorphous aCa-polyP-MP (350 nm; Fig.1).

In the next step, we investigated whether those particles could also be formed under more physiological conditions in situ, using dissolved HA and Na-polyP as starting materials. If those two components, readily soluble in aqueous milieu, were supplemented with $\mathrm{Mg}^{2+}$ they formed a three components system (HA- $\mathrm{Mg}^{2+}-\mathrm{Na}$-polyP) that was highly viscous with a paste-like consistency (Fig. 5). It is importantly to mention that under higher SEM magnification it becomes obvious that the paste was composed of globular microparticles with dimensions of about $400 \mathrm{~nm}$ (Fig. 6). The $\mathrm{Ca}^{2+}$ concentration in the synovial fluid has been determined to be $0.512 \mathrm{mg} / \mathrm{dL}$ in asymptomatic patients, while a higher level of $0.8 \mathrm{mg} /$ $\mathrm{dL}$ has been determined in the symptomatic group with temporomandibular joint pathology (Aghabeigi et al., 2002). In comparison, the $\mathrm{Mg}^{2+}$ concentration in the synovial fluid is about 5-fold lower (Krachler et al., 2000). For these studies, we used $\mathrm{Mg}^{2+}$ for cross-linking of HA with polyP, since this complex was more readily soluble in comparison to Ca-polyP, especially in the presence of the enzyme ALP (to be published), and in turn was more suitable for a potential future clinical application.

It is important to note that $\mathrm{Mg}^{2+}$ indeed interacts with $\mathrm{HA}$ and polyP by ionic bonds. This salt-formation is stable, at least during a $90 \mathrm{~min}$ incubation period in saline. However, if the three components reaction (HA, polyP and $\mathrm{Mg}^{2+}$ ) was performed in the presence of synovial fluid, a time-dependent decrease of the interaction is measured at $30{ }^{\circ} \mathrm{C}$ during the $90 \mathrm{~min}$ incubation period. This effect can be attributed to the hyaluronidase and/or alkaline phosphatases that are present in the synovial fluid (Nagaya et al., 1999; Trumble et al., 2007).
Importantly, the HA- $\mathrm{Mg}^{2+}$-Na-polyP matrix promotes strongly the adhesion of chondrocytes to the culture dishes, even in comparison to HA alone (Fig. 7). This high cell compatibility of the $\mathrm{HA}-\mathrm{Mg}^{2+}-\mathrm{Na}$-polyP matrix was also reflected by the degree of gene inducibility elicited by this paste in comparison the free HA or Na-polyP. The qRT-PCR studies revealed that the gene encoding the transcription factor SOX9, which regulates chondrocyte differentiation, proliferation and entry into hypertrophy in immature and proliferating chondrocytes (Leung et al., 2011), was only significantly upregulated after a $21 \mathrm{~d}$ incubation period in chondrocytes in comparison to the controls (without any component), to HA or to Na-polyP alone. Likewise, the paste strongly enhanced the expression of collagen 3A1 (COL3A1), a cartilage matrix protein, marker for differentiation of chondrocytes both in vivo and in vitro (Aigner et al., 1997). This gene was strongly upregulated after growing the chondrocytes onto HA$\mathrm{Mg}^{2+}$-Na-polyP and only moderately stimulated by HA. Recently, we also found that the steady-state expression of two further genes, markers for cartilage formation, collagen 2 and aggrecan, strongly increased after incubation of human chondrocytes with $\mathrm{HA}-\mathrm{Mg}^{2+}$-Na-polyP, while HA and soluble polyP elicited no significant effect (Müller et $a l ., 2016)$. It is well established that chondrocytes undergo dedifferentiation during in vitro cultivation; a process that is accompanied by substantial changes of the chondrocyte gene expression profile, alterations in the composition of the extracellular matrices or the expression of cell surface receptors (Cucchiarini et al., 2014). This important question has not yet been studied by us, along with the polyP matrices.

A further significant outcome of the present study is the finding that the synovial fluid contains polyP in the size range of about 80 units of phosphate (Fig. 9). Hence, this size matches the medium-chain polyP, secreted from activated human platelets (reviewed in: Morrissey et al., 2012). Since blood platelets accumulate in synovial fluid, especially after inflammation, we propose that polyP is released in this compartment by those cells. The finding that synovial fluid increased the steady-state expression of COL3A1, the marker gene for chondrocyte differentiation (Fig. 10) was interesting. At a dilution of 1:100, even the low concentration of $10 \mu \mathrm{L}$ per well, expression was stimulated by 9.6 -fold. If the synovial fluid was preincubated with ALP, an enzyme that specially hydrolyses polyP (Lorenz and Schröder, 2001), the stimulating function was completely abolished. In turn, these data can be taken as strong evidence that it is the polyP, present in the synovial fluid that causes the induction of the COL3A1 gene.

\section{Conclusion}

The data summarised in this study underscore the importance in the synovial fluid of polyp, which is synthesised in the blood platelets as a - perhaps crucial - factor in the stimulation of the chondrocytes. This conclusion is based on the performed steady-state 
expression studies. It is shown that COL3A1, encoding for one major extracellular matrix structure of the cartilage (Le Goff et al., 2006), as well as the transcription factor SOX9 are highly expressed. The latter transcription factor is upregulated not only during embryogenesis but also during cartilage regeneration (Bi et al., 1999). Therefore, we propose that polyP, injected into the synovial fluid, might ameliorate or even reverse the adverse symptoms of osteoarthritis. One route which might be advisable to follow is the application of amorphous $\mathrm{Mg}^{2+}$-polyP microparticles, fabricated in the absence or presence of HA. Due to the high propensity of amorphous $\mathrm{Mg}^{2+}$-polyP microparticles to de-assemble through cleavage of the ionic bonds in aqueous solution and allow $\mathrm{Ca}^{2+}$ to form $\mathrm{Ca}^{2+}$ polyP, it can be assumed that the latter $\mathrm{Ca}^{2+}$ polyP particles can form a durable polyP layer. The ALP, released by the chondrocytes, can support this dynamic exchange of $\mathrm{Mg}^{2+}$ by $\mathrm{Ca}^{2+}$. Since HA exposes, like polyP, anionic groups which can crosslink polyP through $\mathrm{Ca}^{2+}$, the two polymers (polyP and HA) can form the new cartilaginous layer. In complex with polyP, HA might also be protected against enzymatic degradation by hyaluronidase (Caygill and Ali, 1969). Using this approach, we are optimistic that relief of osteoarthritis, through a short or long-term management using natural organic (HA) and inorganic polyP, might be possible.

\section{Acknowledgements}

We are very thankful to Prof P. Drees (Clinic of Orthopaedics and Orthopaedic Surgery, University Medical Centre Mainz) for the provision of human synovial fluid. WEG Müller is a holder of an ERC Advanced Investigator Grant (No. 268476 "BIOSILICA") and of an ERC-2014-PoC Grant (No. 662486 "MorphoVESPoC"). This work was supported by grants from the Deutsche Forschungsgemeinschaft (Schr 277/10-3), the European Commission ("Bio-Scaffolds: Customised Rapid Prototyping of Bioactive Scaffolds", No. 604036; and "BlueGenics": No. 311848), the International Human Frontier Science Program and the BiomaTiCS research initiative of the University Medical Centre, Mainz.

\section{References}

Aghabeigi B, Cintra N, Meghji S, Evans A, Crean SJ (2002) Temporomandibular joint synovial fluid sampling: estimation of dilution factor using calcium ion concentration. Int J Oral Maxillofac Surg 31: 646-649.

Ahlqvist J, Osterlund K, Harilainen A (1989) Does joint cartilage require energy? Ann Rheum Dis 48: 878.

Aigner T, Glückert K, von der Mark K (1997) Activation of fibrillar collagen synthesis and phenotypic modulation of chondrocytes in early human osteoarthritic cartilage lesions. Osteoarthritis Cartilage 5: 183-189.

Akmal M, Singh A, Anand A, Kesani A, Aslam N, Goodship A, Bentley G (2005) The effects of hyaluronic acid on articular chondrocytes. J Bone Joint Surg Br 87: 1143-1149.
Bailey AJ, Mansell JP, Sims TJ, Banse X (2004) Biochemical and mechanical properties of subchondral bone in osteoarthritis. Biorheology 41: 349-358.

Bi W, Deng JM, Zhang Z, Behringer RR, de Crombrugghe B (1999) Sox9 is required for cartilage formation. Nature Gen 22: 85-89.

Caygill JC, Ali Z (1969) Degradation of synovial fluid and hyaluronic acid by serum and testicular hyaluronidase, and by L-ascorbic acid and the effect of inhibitors. Clin Chim Acta 26: 395-400.

Clark JE, Beegen H, Wood HG (1986) Isolation of intact chains of polyphosphate from Propionibacterium shermanii grown on glucose or lactate. J Bacteriol 168: 1212-1219.

Crobu M, Rossi A, Mangolini F, Spencer ND (2012) Chain-length-identification strategy in zinc polyphosphate glasses by means of XPS and ToF-SIMS. Anal Bioanal Chem 403: 1415-1432.

Cucchiarini M, Madry H, Guilak F, Saris DB, Stoddart MJ, Koon Wong M, Roughley P (2014) A vision on the future of articular cartilage repair. Eur Cell Mater 27: 1216.

Day JS, Ding M, van der Linden JC, Hvid I, Sumner DR, Weinans H (2001) A decreased subchondral trabecular bone tissue elastic modulus is associated with pre-arthritic cartilage damage. J Orthop Res 19: 914-918.

Decker B, McGuckin WF, McKenzie BF, Slocumb CH (1959) Concentration of hyaluronic acid in synovial fluid. Clin Chem 5: 465-469.

Elfervig MK, Graff RD, Lee GM, Kelley SS, Sood A, Banes AJ (2001) ATP induces $\mathrm{Ca}(2+)$ signaling in human chondrons cultured in three-dimensional agarose films. Osteoarthritis Cartilage 9: 518-526.

Farr M, Wainwright A, Salmon M, Hollywell CA, Bacon PA (1984) Platelets in the synovial fluid of patients with rheumatoid arthritis. Rheumatol Int 4: 13-17.

Findlay DM (2007) Vascular pathology and osteoarthritis. Rheumatology (Oxford). 46: 1763-1768.

Fox AJS, Bedi A, Rodeo SA (2009) The basic science of articular cartilage: structure, composition, and function. Sports Health 1: 461-468.

Gibilisco P, Schumacher HJ, Hollander J, Soper K (1984) Synovial fluid crystals in osteoarthritis. Arthritis Rheum 28: 511-515.

Girotto D, Urbani S, Brun P, Renier D, Barbucci R, Abatangelo G (2003) Tissue-specific gene expression in chondrocytes grown on three-dimensional hyaluronic acid scaffolds. Biomaterials 24: 3265-3275.

Imsiecke G, Münkner J, Lorenz B, Bachinski N, Müller WEG, Schröder HC (1996) Inorganic polyphosphates in the developing freshwater sponge Ephydatia muelleri: effect of stress by polluted waters. Environ Toxicol Chem 15: $1329-1334$.

Jerosch J (2011) Effects of glucosamine and chondroitin sulfate on cartilage metabolism in OA: outlook on other nutrient partners especially omega-3 fatty acids. Int $\mathrm{J}$ Rheumatol 2011: 969012.

Karsenty G, Kronenberg HM, Settembre C (2009) Genetic control of bone formation. Annu Rev Cell Dev Biol 25: 629-648. 
Kiani C, Chen L, Wu YJ, Yee AJ, Yang BB (2002) Structure and function of aggrecan. Cell Res 12: 19-32.

Koolpe M, Pearson D, Benton HP (1999) Expression of both $\mathrm{P} 1$ and $\mathrm{P} 2$ purine receptor genes by human articular chondrocytes and profile of ligand-mediated prostaglandin E2 release. Arthritis Rheum 42: 258-267.

Kotlarz H, Gunnarsson CL, Fang H, Rizzo JA (2009) Insurer and out-of-pocket costs of osteoarthritis in the US: evidence from national survey data. Arthritis Rheum 60: 3546-3553.

Krachler M, Domej W, Irgolic KJ (2000) Concentrations of trace elements in osteoarthritic knee-joint effusions. Biol Trace Elem Res 75: 253-263.

Lamontagne CA, Plante GE, Grandbois M (2011) Characterisation of hyaluronic acid interaction with calcium oxalate crystals: implication of crystals faces, $\mathrm{pH}$ and citrate. J Mol Recognit 24: 733-740.

Le Goff C, Somerville RP, Kesteloot F, Powell K, Birk DE, Colige AC, Apte SS (2006) Regulation of procollagen amino-propeptide processing during mouse embryogenesis by specialisation of homologous ADAMTS proteases: insights on collagen biosynthesis and dermatosparaxis. Development 133: 1587-1596.

Leung VY, Gao B, Leung KK, Melhado IG, Wynn SL, Au TY, Dung NW, Lau JY, Mak AC, Chan D, Cheah KS (2011) SOX9 governs differentiation stage-specific gene expression in growth plate chondrocytes via direct concomitant transactivation and repression. PLoS Genet 7: e1002356.

Lorenz B, Schröder HC (2001) Mammalian intestinal alkaline phosphatase acts as highly active exopolyphosphatase. Biochim Biophys Acta 1547: 254261.

Mathy-Hartert M, Hogge L, Sanchez C, Deby-Dupont G, Crielaard JM, Henrotin Y (2008) Interleukin-1beta and interleukin-6 disturb the antioxidant enzyme system in bovine chondrocytes: a possible explanation for oxidative stress generation. Osteoarthritis Cartilage 16: 756-763.

McCarthy GM, Cheung HS (2009) Point: hydroxyapatite crystal deposition is intimately involved in the pathogenesis and progression of human osteoarthritis. Curr Rheumatol Rep 11: 141-147.

Mobasheri A, Vannucci SJ, Bondy CA, Carter SD, Innes JF, Arteaga MF, Trujillo E, Ferraz I, Shakibaei M, Martín-Vasallo P (2002) Glucose transport and metabolism in chondrocytes: a key to understanding chondrogenesis, skeletal development and cartilage degradation in osteoarthritis. Histol Histopathol 17: 1239-1267.

Morrissey JH, Choi SH, Smith SA(2012) Polyphosphate: an ancient molecule that links platelets, coagulation, and inflammation. Blood 119: 5972-5979.

Moss DW, Eaton RH, Smith JK, Whitby LG (1967) Association of inorganic pyrophosphatase activity with human alkaline-phosphatase preparations. Biochem J 102: 53-57.

Müller WEG, Tolba E, Schröder HC, Wang XH (2015a) Polyphosphate: a morphogenetically active implant material serving as metabolic fuel for bone regeneration. Macromolec Biosci 15: 1182-1197.

Müller WEG, Tolba E, Schröder HC, Wang S, Glaßer G, Muñoz-Espí R, Link T, Wang XH (2015b) A new polyphosphate calcium material with morphogenetic activity. Materials Letters 148: 163-166.

Müller WEG, Tolba E, Schröder HC, Neufurth M, Wang S, Link T, Al-Nawas B, Wang XH (2015c) A new printable and durable N,O-carboxymethyl chitosan-Ca2+polyphosphate complex with morphogenetic activity. J Mat Chem B 3: 1722-1730.

Müller WEG, Tolba E, Schröder HC, Diehl-Seifert B, Wang XH (2015d) Retinol encapsulated into amorphous $\mathrm{Ca}(2+)$ polyphosphate nanospheres acts synergistically in MC3T3-E1 cells. Eur J Pharm Biopharm 93: 214-223.

Müller WEG, Ackermann M, Tolba E, Neufurth M, Wang S, Schröder HC, Wang XH (2016) A bio-imitating approach to fabricate an artificial matrix for cartilage tissue engineering using magnesium-polyphosphate and hyaluronic acid. RSC Adv 6, 88559-88570.

Murray CJ, Lopez AD (1997) Global mortality, disability, and the contribution of risk factors: global burden of disease study. Lancet 349: 1436-1442.

Nabiyouni M, Ren Y, Bhaduri SB (2015) Magnesium substitution in the structure of orthopedic nanoparticles: A comparison between amorphous magnesium phosphates, calcium magnesium phosphates, and hydroxyapatites. Mater Sci Eng C Mater Biol Appl 52: 11-17.

Nagaya H, Ymagata T, Ymagata S, Iyoda K, Ito H, Hasegawa Y, Iwata H (1999) Examination of synovial fluid and serum hyaluronidase activity as a joint marker in rheumatoid arthritis and osteoarthritis patients (by zymography). Ann Rheum Dis 58: 186-188.

Nanke Y, Kotake S, Akama H, Kamatani N (2002) Alkaline phosphatase in rheumatoid arthritis patients: possible contribution of bone-type ALP to the raised activities of ALP in rheumatoid arthritis patients. Clin Rheumatol 21: 198-202.

National collaborating centre for chronic conditions (UK) (2008) Osteoarthritis: national clinical guideline for care and management in adults. National Institute for Health and Clinical Excellence: guidance. Royal College of Physicians, London. PMID:21290638

Nguyen C, Bazin D, Daudon M, Chatron-Colliet A, Hannouche D, Bianchi A, Côme D, So A, Busso N, Busso N, Lioté F, Ea HK (2013) Revisiting spatial distribution and biochemical composition of calcium-containing crystals in human osteoarthritic articular cartilage. Arthritis Res Ther 15: R103.

Nitzan DW, Nitzan U, Dan P, Yedgar S (2001) The role of hyaluronic acid in protecting surface-active phospholipids from lysis by exogenous phospholipase A(2). Rheumatology (Oxford) 40: 336-340.

O'Neill WC (2006) Pyrophosphate, alkaline phosphatase, and vascular calcification. Circ Res 99: e2.

Pacifici M, Golden EB, Oshima O, Shapiro IM, Leboy PS, Adams SL (1990) Hypertrophic chondrocytes. The terminal stage of differentiation in the chondrogenic cell lineage? Ann N Y Acad Sci 599: 45-57.

Petrie A, Watson P (2013) Statistics for veterinary and animal science. Wiley-Blackwell: 85-99.

Pfaffl MW (2001) A new mathematical model for relative quantification in real-time RT-PCR. Nucleic Acids Res 29: e45. 
Pilliar RM, Filiaggi MJ, Wells JD, Grynpas MD, Kandel RA(2001) Porous calcium polyphosphate scaffolds for bone substitute applications - in vitro characterisation. Biomaterials 22: 963-972.

Pritzker KP (2009) Counterpoint: hydroxyapatite crystal deposition is not intimately involved in the pathogenesis and progression of human osteoarthritis. Curr Rheumatol Rep 11: 148-153.

Raeissadat SA, Rayegani SM, Hassanabadi H, Fathi M, Ghorbani E, Babaee M, Azma K (2015) Knee osteoarthritis injection choices:platelet-rich plasma (PRP) versus hyaluronic acid (a one-year randomised clinical trial). Clin Med Insights Arthritis Musculoskelet Disord 8: 1-8.

Raynaud S, Champion E, Bernache-Assollant D, Thomas P (2002) Calcium phosphate apatites with variable $\mathrm{Ca} / \mathrm{P}$ atomic ratio I. Synthesis, characterisation and thermal stability of powders. Biomaterials 23: 1065-1072.

Rosenthal AK (2011) Crystals, inflammation, and osteoarthritis. Curr Opin Rheumatol 23: 170-173.

Roughley PJ, Lee ER (1994) Cartilage proteoglycans: structure and potential functions. Microsc Res Tech 28 : 385-397.

Ryan LM, Rachow JW, McCarty DJ (1991) Synovial fluid ATP: a potential substrate for the production of inorganic pyrophosphate. J Rheumatol 18: 716-720.

Salminen H, Vuorio E, Säämänen AM (2001) Expression of Sox 9 and type IIA procollagen during attempted repair of articular cartilage damage in a transgenic mouse model of osteoarthritis. Arthritis Rheum 44: 947-955.

Schmidt TA, Sah RL (2007) Effect of synovial fluid on boundary lubrication of articular cartilage. Osteoarthritis Cartilage 15: 35-47.

Sharma AR, Jagga S, Lee SS, Nam JS (2013) Interplay between cartilage and subchondral bone contributing to pathogenesis of osteoarthritis. Int J Mol Sci 14: $19805-$ 19830.

Silver FH, Bradica G, Tria A (2002) Elastic energy storage in human articular cartilage: estimation of the elastic modulus for type II collagen and changes associated with osteoarthritis. Matrix Biol 21: 129-137.

Sivan SS, Wachtel E, Roughley P (2014) Structure, function, aging and turnover of aggrecan in the intervertebral disc. Biochim Biophys Acta 1840: 3181-3189.

Starlinger H, Lübbers DW (1976) Oxygen consumption of the isolated carotid body tissue (cat). Pflugers Arch 366: 61-66.
St-Pierre JP, Gan L, Wang J, Pilliar RM, Grynpas MD, Kandel RA (2012) The incorporation of a zone of calcified cartilage improves the interfacial shear strength between in vitro-formed cartilage and the underlying substrate. Acta Biomater 8: 1603-1615.

Szumera M (2014) Structural investigations of silicatephosphate glasses containing $\mathrm{MoO}_{3}$ by FTIR, Raman and 31P MAS NMR spectroscopies. Spectrochim Acta A Mol Biomol Spectrosc 130: 1-6.

Tchetina EV (2011) Developmental mechanisms in articular cartilage degradation in osteoarthritis. Arthritis 2011: 683970 .

Tew WP, Hackett RP (1981) Identification of cartilage wear fragments in synovial fluid from equine joints. Arthritis Rheum 24: 1419-1424.

Trumble TN, Brown MP, Merritt KA, Billinghurst RC (2007) Joint dependent concentrations of bone alkaline phosphatase in serum and synovial fluids of horses with osteochondral injury: an analytical and clinical validation. Osteoarthritis Cartilage 16: 779-786.

Wang X, Schröder HC, Müller WEG (2016) Polyphosphate as a metabolic fuel in Metazoa: a foundational breakthrough invention for biomedical applications. Biotechnol J 11: 11-30.

Wiens M, Wang X, Schloßmacher U, Lieberwirth I, Glasser G, Ushijima H, Schröder HC, Müller WEG (2010) Osteogenic potential of bio-silica on human osteoblast-like (SaOS-2) cells. Calcif Tissue Int 87: 513-524.

Yamakura T, Bertaccini E, Trudell JR, Harris RA (2001) Anesthetics and ion channels: molecular models and sites of action. Annu Rev Pharmacol Toxicol 41: 23-51.

Yang L, Tsang KY, Tang HC, Chan D, Cheah KS (2014) Hypertrophic chondrocytes can become osteoblasts and osteocytes in endochondral bone formation. Proc Natl Acad Sci USA 111: 12097-12102.

Yifen J, Dehua J, Xiangsheng C, Behya B, Xihuai $H$ (1986). Raman spectrum studies of the glasses in the system Na2O/A12O/P2O5. J Non-Cryst Solids 80: 147-151

Editor's note: The Scientific Editor responsible for this paper was Martin Stoddart. 